\title{
Deconstructing Functional Organisation of Newspaper Discourse
}

\author{
Radzuwan Ab Rashid (Corresponding author) \\ Centre of English Language Studies, Faculty of Languages and Communication \\ Universiti Sultan Zainal Abidin, Gong Badak Campus, 21300 Kuala Nerus, Terengganu, Malaysia \\ E-mail: radzuwanrashid@unisza.edu.my \\ Kamariah Yunus \\ Centre of English Language Studies, Faculty of Languages and Communication \\ Universiti Sultan Zainal Abidin, Gong Badak Campus, 21300 Kuala Nerus, Terengganu, Malaysia \\ E-mail: kamariah@unisza.edu.my \\ Zanirah Wahab \\ Centre of English Language Studies, Faculty of Languages and Communication \\ Universiti Sultan Zainal Abidin, Gong Badak Campus, 21300 Kuala Nerus, Terengganu, Malaysia \\ E-mail: zanirah@unisza.edu.my
}

Received: 12-06-2016

Published: 01-11-2016
Accepted: 19-08-2016

doi:10.7575/aiac.ijalel.v.5n.6p.183
Advance Access Published: September 2016

URL: http://dx.doi.org/10.7575/aiac.ijalel.v.5n.6p.183

\begin{abstract}
This paper aims to shed light on the functional organisation of language in the reports published in Malaysian newspapers. Adopting Halliday's $(1970 ; 1990 ; 1994)$ systemic functional grammar as its analytical lens, two text extracts, one from New Strait Times (NST) and one from The Star, were scrutinized. Both reports cover an urge to improve the standard of sub-standard National Service camps. The analysis shows that NST report uses a serious and aggressive tone while The Star report is less serious and less aggressive. Interestingly, both The Star and New Strait Times are considered as right-wing and formal Malaysian newspapers instead of the 'Tabloid' ones. This paper argues that even though the differences in the organisation of the language are subtle, the two reports convey different messages to readers and possibly leave different impacts on them.
\end{abstract}

Keywords: Halliday, functional grammar, newspaper discourse, New Strait Times, The Star, Malaysia

\section{Introduction}

Language use is a purposeful behaviour. Authors, especially journalists, write to convey particular messages to readers. As pointed out by Halliday and Matthiessen (2004), language is functional because its system networks serve as the resources to produce meaning. Deconstructing messages conveyed in newspaper reports requires a careful consideration of the systemic and functional aspects of the texts instead of the formal language structure emphasized in the framework of traditional grammar.

Before proceeding any further, it is important to state our personal position in relation to the extracts analysed in this paper. We see National Service Training Programme as one of the national agendas in building up a nation. Because of that, we expect any discussion or comments related to this programme should be done in a serious manner. This expectation influences our interpretation of the two extracts, so the rest of this paper especially in 'Analysis and Discussion' should be read with this in mind.

\subsection{National Service Training Programme in Malaysia}

The National Service Training Programme started in December 2003 and it aims to promote unity among youths from different races and ethnic groups so that racial polarisation can be avoided thus maintaining the harmony in the country. A total of 84 camps were set up across the country where conscripts are exposed to four different modules: i) physical; ii) nation building; iii) character building; and iv) community service. The conscripts, who are 18 years of age and chosen randomly from a national database, are required to complete these modules within the period of three months.

Every year, the government allocates more than RM550 million for this programme ("RM2.37bil Spent on NS," 2008). However, the government is not satisfied with the current standard of the camps and the Deputy Prime Minister urges the camp operators to improve their standard. It is the news about this urge that has been chosen to be analysed in this paper. By choosing two reports on the same issue, we hope to show that different ways of organising language can convey different messages to readers and possibly leave different impacts on them. 


\section{An Overview of Functional Grammar}

The lexico-grammatical patterns which are prevalent in specialised texts constitute the construction of knowledge, and they play specific functions in the texts. Firth, the Father of Collocation, proposes that 'meaning is function in context', and there is no separation between grammar and lexis. To the neo-Firthians such as Sinclair (1991), Halliday (1990) and Hoey (2004), each grammatical or lexical unit is always combined with other linguistic units residing at the right or left of the linguistic environment at the paradigmatic level of a clause. The word combination (a lexico-grammatical pattern) is interrelated with other phrases to form textual cohesion in a sentence in both written and spoken texts. Some lexico-grammatical units or word combinations such as idioms are fixed that they have figurative rather than literal meanings. The idiom to kick the bucket, for example, means to die rather than literally and physically kicking a bucket. According too Firth (1957), the linguistic choices that a speaker made are always influenced by 'context of situation'; that is, the linguistic environment (immediate context) and the culture or 'discourse community' that speaks the language (a wider context) (Swales, 1990). The most frequently used phrases in specialised texts are habitual and repetitive, and they can be observed, for example, by using a concordancer to concordance the lines in small or large corpora.

Even though the Firthians believe that language can be seen as a system of choices, the neo-Firthians such as Sinclair and Halliday took different approaches to the analysis of patterns of organisation of texts, such as newspaper articles. While Sinclair $(1991,1998)$ takes a quantitative approach to the study of phraseology in texts (e.g. corpora) in order to propose a theory for grammar, Halliday (1994) takes a qualitative and 'systemic' approach to analyse patterns of organisation of specialised texts. In his Systemic Functional Grammar (SFG), he contends that every sentence in a text is multifunctional, and it consists of three interrelated metafunctions which are "woven together into the same linguistic unit" (Hasan, 2009, p. 9). In other words, realisations of these three metafunctions (the semantic component of the SFG model) occur simultaneously, allowing language to create different meanings at the same time (Eggins, 2004). These metafunctions include ideational (construes human experience), interpersonal (enacts human relationship), and textual (creates discourse). Ideational metafunction is further divided into experiential and logical functions, while interpersonal metafunction is further classified as mood and residue. Textual metafunction, on the other hand, has two elements - theme and rheme. Theme is defined as the clause initial position, while the remainder of the clause is called rheme.

The experiential function, which is part of the ideational function, "describe events and states and the entities involved in them" (Thompson, 2004, p.30). The three main elements in experiential function are participant, process, and circumstance. The participant can be termed as agent or actor. Process includes material (doing and causing), mental (thinking, sensing, evaluating), verbal (saying), existential (existing, appearing), and behavioural (acting). Circumstance informs us about manner, place, temporal, duration, role, or purpose of a state or action. For example, in a clause: Thousands of people were evacuated in the 1980s, Thousands of people is the participant, were evacuated is the process, and in the 1980s is the circumstance. The logical function, on the other hand, construes logical links between two events based on the schemata or experience that a speaker has. A speaker can figure out what might happen in the future based on the previous experience. On the whole, the ideational metafunction relates to the field aspects of a text or its subject matter and context of use.

Halliday and Mathiessen (2004) regard interpersonal function as expressing mood and residue. Mood comprises of Subject + Finite (the first of the verbal group). Residue, on the other hand, is the predicator (the rest of the verbal group plus complement or expansion). Therefore, in a sentence: Hani can speak English, Hani can is the Mood and speak English is the Residue. In this case, modal adjuncts are included in the mood, and can be categorised into mood adjuncts (e.g. probably) and comment adjuncts (e.g. unfortunately). In all, the interpersonal metafunction relates to a text's aspects of tenor or interactivity.

In SFG, every clause has its thematic structure. In line with the three metafunctions, theme has been further categorised as topical (experiential) theme, interpersonal theme, and textual theme. In English, theme is realised by what is placed in initial position within the clause, and this initial position gives the theme a 'special status' within the clause (Halliday, 1994). Theme also plays a very crucial role in organising the message, and it may heavily impact the readers. Theme and rheme is also related to the Given and New information in a clause. Given (theme) is the previous information, while New information is the rheme. Theme is either marked or unmarked. In declarative sentences, the unmarked theme (underlined) is the subject (e.g. The two students slept well), while the marked theme (underlined) is an adverbial (e.g. Across the river, they found the ship). The textual metafunction relates to mode, the internal organisation and communicative nature of a text. This comprises textual interactivity (disfluencies such as hesitators, pauses and repetitions), spontaneity (lexical density, grammatical complexity, coordination and the use of nominal groups), and communicative distance (textual cohesion). The author's stance is conveyed by the theme in a clause.

\section{Methodology}

Textual analysis can be divided into two: i) focusing on the text as an object in its own right; ii) focusing on the text as an instrument for finding out about something else (Halliday and Matthiessen, 2004). When focusing on text as an object, two questions are central, which are 'Why does the text mean what it does?' and 'Why is it valued as it is'? On the other hand, when focusing on text as in instrument, researchers will be asking what the text reveals about the system of the language. This study treated the reports as both the object and the instrument. As higlighted by Halliday and Matthiessen (2004), these two perspectives are complementary in the sense that; 
we cannot explain why a text means what it does, with all the various readings and values that may be given to it, except by relating it to the linguistic system as a whole; and equally, we cannot use it as a window on the system unless we understand what it means and why (p. 3).

The two reports were purposively sampled based on the potential of rich data for functional analysis. Among the foci of analysis are field, tenor, mode, lexico-grammatical choices, mood, and styles. Both reports address the same issue in a slightly different manner. By choosing these two reports, we hope to provide insights into the possible impacts produced by texts with different language organisations.

\section{Discussion and Analysis}

\subsection{Field, Tenor, and Mode}

Both extracts, even though written in different tones and attitudes, share the same field, tenor, and mode, as shown in Table 1. This is because the extracts are within the same genre, which is newspaper report.

Table 1. Field, tenor, and mode of the extracts

\begin{tabular}{ll}
\hline Field & The warning to sub-standard NS camps to improve the standard. If there \\
is no improvement in the standard, the camp operators will be punished \\
by the government. This is clearly conveyed through the headline of the \\
texts and contents that follow. \\
The reporter is directing the article to newspaper readers. The readers \\
can be divided into two; the general newspaper readers and the camp \\
operators who read the newspaper. This is set by quoting and reporting \\
Deputy Prime Minister's words, such as action will be taken so that the \\
readers are aware of the government's affirmation. \\
\hline Mode & Report to disseminate government's warning from formal newspapers. \\
\hline
\end{tabular}

\subsection{Headlines}

The headline of NST is Action against sub-standard National Service camps whilst the headline for The Star is Government eye on National Service camps and trainers. These two different headlines set the different tones for the texts that follow. The lexico-grammatical choices in NST headline give it an aggressive and serious tone whereas The Star comes across as more neutral and less aggressive and lighter. The first two words of action against in NST give stronger impact and more serious tone compared to government eye in The Star. For NST, the warning is explicit that action will be taken in that case while in The Star, eyeing the camps does not really give us idea of taking an action. This is because we can still argue that government can just eye the camp but no action to the camp operators will follow after eyeing the camp. It is common for journalists to construct uncertainty in news reporting. For instance, Bailey, Giangola, and Boykoff (2014) found that journalists for New York Times and Wall Street Journal from the USA and El Pais and El Mundo from Spain use high density of epistemic markers and ambiguous grammatical constructs of uncertainty in their news. The uncertainty in the headline makes The Star appears to be less aggressive compared to the headline in NST as it insinuates the warning implicitly.

In addition, when referring to the camps, the NST adds an adjective sub-standard. In contrast, The Star just refers to the camps as National Service camps. This adjective does specify the matter that is going to be discussed in the text, which is the camps that do not fulfill the requirement needed. Thus, NST headline presets readers' minds that something serious, which is the failure to fulfill the requirement, is going to be discussed in the text. The use of adjectives reflect the journalist's sentiment of the issue being reported (Padmaja, Fatima, Bandu, 2014). It is reasonable to suggest that the NST journalist views sub-standard camp as a big problem in NS programme.

\subsection{Paragraph One}

NST Seremban: Action will be taken against National Service camp operators who fail to maintain basic safety and operational standards set by the National Service Training Department, Datuk Seri Najib Razak said

(Sentence 1)

The Star Seremban: The government will closely monitor conditions at National Service camps and keep an eye on the trainers, Deputy Prime Minister Datuk Seri Najib Tun Razak said.

(Sentence 1)

The first paragraph of NST report repeats the headline and adds a few additional facts which is the action will be taken against camp operators who fail to maintain basic safety and operational standards set by the National Service Training Department. In this line, the reporter uses modal will instead of would. The use of will suggests a strong certainty of government taking the action in the future. Witte, Hollevoet, Dobruszkes, Hubert, and Macharis (2013) point out that 
modal choice can take place consciously or unconsciously. However, we agree with reseachers who view language as a purposeful behaviour such as Benwell and Stokoe (2006), Bamberg (2011), Edwards and Potter (2005), and Rashid, Rahman, and Rahman (2016). Unlike spoken discourse which requires real-time processing (Trenkic, Mirkovic, \& Altmann, 2014), written discourse can be crafted beforehand (Rashid, 2016; Rashid et al., 2016). To add seriousness to the tone, the reporter chooses a marked theme instead of an unmarked one. Theme is an element that serves as the point of departure, identified by its position in the clause (Halliday, 2004). It is very important in presenting the elements of author-voice (Bakaa, 2015). By choosing the marked theme, the reporter attempts to show which part of the message is considered most worthy of attention, that is, the action. This makes the threat stated by the government to the camp operators very explicit.

To some extent, bias is discernible in the first paragraph of NST that the reporter favours the government rather than the camp operators. This is reflected in the use of adjective basic to describe the safety to be maintained. In other words, the reporter is trying to tell us that the government is not being cruel to the camp operators. Unless if they fail to maintain basic safety, not the higher level one, only then will the government take action against them. This finding resonates with Padmaja, Fatima, and Bandu (2014) that adjective can be strategically used to reflect authors' sentiment towards the issue being reported.

In comparison, the first paragraph of The Star is less serious than the first paragraph of NST. This is done by having an unmarked theme which is the government that follows subject + verb order. This is the typical pattern in a declarative clause in which theme is conflated with subject (Halliday and Matthiessen, 2004). The government is an unmarked theme as it is obvious that only the government has the power to deal with any problem in the implementation of National Service Training Programme. Therefore, the actual interesting point that readers want to know is how the government reacts to the problem. Will the government take any action or simply sit-still? Besides that, the reporter chooses to use will closely monitor as the process compared to will be taken in the NST. As pointed out earlier, the word monitor merely suggests that government will keep an eye on the camps. Readers are left unsure whether the camp operators will be punished.

\subsection{Paragraph Two}

The difference in the level of seriousness in Paragraph Two of both reports can be made clear by scrutinizing their verbal processes, as shown in Table 2.

Table 2. Verbal processes in the second paragraph of the reports

\begin{tabular}{|c|c|c|c|c|}
\hline & Sayer & Verb & Addressee & Saying \\
\hline $\begin{array}{l}\text { The } \\
\text { Star }\end{array}$ & $\begin{array}{l}\mathrm{He} \quad \text { (Deputy } \\
\text { Prime Minister) }\end{array}$ & said & & $\begin{array}{l}\text { appropriate action would be taken } \\
\text { to ensure the proceeds without } \\
\text { hitches. } \\
\text { (Sentence 1) }\end{array}$ \\
\hline NST & $\begin{array}{l}\text { The Deputy } \\
\text { Prime Minister }\end{array}$ & warned & $\begin{array}{l}\text { camp } \\
\text { operators }\end{array}$ & $\begin{array}{l}\text { that the department was monitoring } \\
\text { the overall situation at all National } \\
\text { Service camps throughout the year. }\end{array}$ \\
\hline
\end{tabular}

(Sentence 1)

As we can see in Table 2, the verb used in each sentence is completely different. In The Star, the verb said has a neutral connotation while the verb warned in NST has a very aggressive connotation and at the same time makes the threat explicit. The use of different words when referring to the same event also shows that the reporters write based on their own evaluation and judgement of the event. As pointed by Adeniyi and Bello (2016), strategic choice of words are useful in making known the journalist's intention and persuading readers to understand the message that she/he attempts to convey.

The reporter in The Star does not explicitly mention the addressee while in NST the addressee which is camp operators is clearly stated. By mentioning the addressee, paragraph in NST sounds more aggressive in the sense that it keeps 'attacking' the camp operators directly. It also serves to emphasize the fact that the government is more powerful than the camp operators. That is why the government can address the warning to the camp operators. Hyland (2001) higlights that strategic interpersonal negotiations is central in writer-reader dialogue in which "writers seek to balance claims for the significance, originality, and truth of their work against the convictions of their readers" (p. 550).

The saying of the two sentences are also completely different. The use of adjective appropriate contributes to the less aggressive tone in The Star. The adjective appropriate is generally defined as suitable or acceptable in a particular situation. This adjective also represents the neutrality of the reporter in the sense that readers are informed that the government is not cruel to take too heavy action against the camp operators thus reducing their anxiety in dealing with the problem.

The reporter in The Star uses modality would and this indicates less strong certainty compared to the use of will. The use of the modal verb would in this context is different from the use of would in Edwards' (2006) study. Edwards 
examined the use of would in police interrogation and he found that the value of this modal verb is in "its semantics [which] provide for a sense of back-dated predictability with regard to the actions in question" (p. 475). The effect of using the modal would in this newspaper report is that the tone becomes less serious as readers can assume that there is still possibility that the government might cancel the idea of taking actions against the camp operators.

In contrast to the reporter of The Star who uses adjective appropriate to create less aggressive and less serious tone, the reporter in NST uses quantifier all to heighten the seriousness. The quantifier all indicates that not even a single camp is out of this threat and this creates the effect that government will not be bias in taking the action. The reporter seems to warn all camp operators that the government has been monitoring them throughout the year.

4.5 Paragraph Three

The Star "We are monitoring the camps closely, including the environment, facilities, cleanliness and quality of food prepared by the contractors," he said, adding that prior warnings have already been given to camps that did not meet requirements.

(Sentence 1)

NST "We will be evaluating their facilities, level of cleanliness, quality of food and so on".

(Sentence 1)

It is useful to analyse the paragraphs above from the experiential perspective. Both reports take the same actor and goal but different processes. The actor is we (government) and the goal is the camps (facilities, cleanliness, and quality of food). In The Star, the process is are monitoring whilst in NST the process is will be evaluating. Monitoring is generally defined as checking the progress or development regularly and sometimes making comment on it while evaluating is generally defined as considering someone or something in order to make a judgment about them, for example, how good or bad they are. Based on these meanings, it is clear that evaluating has more aggressive and serious connotation thus creates more aggressive and serious tone to the report in NST. Furthermore, warning that has been mentioned repeatedly in NST, is only introduced explicitly for the first time in The Star and it is made as an additional remark thus contributing to the less serious tone in The Star.

4.6 Paragraph Four

Paragraph four in both reports are used to express likelihood based on the conditions, as shown in Table 3.

Table 3. Condition and complication in both reports

\begin{tabular}{lll}
\hline \multicolumn{2}{c}{ Condition } & \multicolumn{2}{l}{ Complication } \\
\hline NST & $\begin{array}{l}\text { If we find these camps do not meet the } \\
\text { standards set }\end{array}$ & we will take action \\
& (Sentence 1) \\
\hline The Star & If there are deficiencies & action will be taken accordingly \\
\end{tabular}

The use of active voice for complication in NST gives more powerful and serious effect to readers in the sense that the reporter is emphasizing the doer thus reminding the camp operators that there is an authority who will take action against them. In contrast, The Star reporter omits the doer and this suggests that the reporter does not intend to emphasize the authority thus creates less aggressive tone in the whole paragraph. The use of active voice in NST is an effective discourse strategy in ensuring the message is grasped by the readers. This is because readers tend to have more difficulty in understanding sentences written in passive voice than active voice (Dabrowska \& Street, 2006).

4.7 Paragraph Five of The Star and Paragraph Six of NST

The Star Najib, who is also Defence Minister, said action would include removing errant trainers or even barring training activity at the camps concerned.

(Sentence 1)

NST Najib, who is also a Defence Minister, said, among others, the government could reduce the number of trainees at non-performing or sub-standard camps.

(Sentence 1)

The two paragraphs are compared because of the similarity in the points, yet presented in slightly different tone. Both paragraphs talk about the action that could be taken by the government, which is removing trainers at the camps. However, when referring to the goal, which is the camps, instead of just saying the camps concerned like what is done in The Star, the NST reporter uses the following compound adjectives: non-performing and sub-standard. These adjectives give more serious and aggressive tone as readers are kept aware about the low quality of the camps concerned. This is the last paragraph in The Star which is relevant to the headline as the remaining paragraphs shift to report about another topic unrelated to National Service Training Programme. 
"Or we can even take more drastic measures by shutting down the camp completely".

(Sentence 1)

This paragraph talks about alternative action that can be taken by the government to deal with the problem, which is shutting down the camp. The reporter successfully creates an aggressive and serious tone by using modal can, adjective drastic and adverb completely. The adjective drastic which means "something extreme" is perhaps used by the reporter to suggest that the government is able to take extreme action against the camp operators if the government wants to. By quoting that the government can shut down the camp completely, the reporter reminds the camp operators that the government is more powerful than them.

4.9 Paragraph Nine of NST

"There have also been warnings given but the situation is not at a serious level yet. We are serious and will not compromise on quality".

(Sentence 1)

It is useful to analyze this paragraph by looking at the mood structure. The mood used here is declarative. The reporter quotes two statements declared by the government, which are "we are serious" and "[we] will not compromise on quality". These two phrases with declarative moods give aggressive and serious tone to the whole paragraph. Furthermore, the reporter uses the modal will which indicates government's strong certainty of the declaration. Bias does exist in the sense that it is up to the reporter in translating the Deputy Prime Minister's words as the original speech is in Malay. Hence, as a reporter who favours the government, the reporter chooses to use will, which is a modal that indicates strong certainty rather than would.

4.10 Paragraph 10 of NST

He said what the ministry wanted now is for all camp operators to improve their premises to comply with the standards set.

(Sentence 1)

This paragraph summarizes the whole purpose of this report by stating what the government wants from the camp operators. The tone is made serious by using a marked theme, which is 'what the ministry wanted now' followed by a rheme "is for all camp operators to improve their premises to comply with the standards set". This marked theme is created by the use of the pseudo-cleft, that is, a sentence that resembles a cleft sentence through the use of a relative clause. In creating a marked theme, authors are actually constructing a thematised constituent. Thematisation is a method of text organisation (Hawes, 2010) which allows writers to organise a particular text in a manner that deliberate emphasis is given to a particular constituent. By using the marked theme, the reporter has succesfully emphasized the point that the government wants to convey to the camp operators.

\section{Conclusion}

This paper has analysed parallel reports in two Malaysian national newspapers (The Star and New Strait Times), of a story of nation interest involving national service camp operators and government. Although both newspapers are the supporters of the government, the NST report comes across as overtly hostile compared to the The Star report. Analysis of the lexico-grammatical differences between these reports shows great similarity in terms of the experiential meanings the two reports convey, but significant differences in interpersonal evaluative meanings: The NST taking every opportunity to intimidateand urge the camp operators and is highly repetitive in doing so. The Star, on the other hand, seems to be less hostile and more neutral in its reporting. This is achieved mainly through different lexical choices and modality use.

The findings discussed in this paper have implications for journalists (the addresser) and readers (the addressee). As for readers, they should not take the newspaper reports for granted as what are being written in the reports are often shaped by the journalists' sentiments, bias, and interpretation of the events being reported. On the other hand, journalists should be made aware of the different effects produced by different sentence structures and diction so that they can strategise their writing to achieve the intended effects. It is recommended for future research to do a contsrastive analysis of two newspaper reports on different issues (e.g. entertainment news versus educational news) as to provide insights into the patterns of writing and examine whether the functional organisation of language is influenced by the different types of news.

\section{References}

Adeniyi, H., \& Bello, O.R. (2016). The choice of diction as empowerment for marital freedom: A study of selected divorce registers in a Nigerian newspaper. International Journal of Humanities and Cultural Studies, $2(2), 56-69$. 
Bailey, A., Giangola, L., \& Boykoff, M.T. (2014). How grammatical choice shapes media representations of climate uncertainty. Environmental Communication, 8 (2), 197-215.

Bakaa, A. J. A. (2015). Functional analysis of marked and unmarked theme in demonstrating a critical argument written by Iraqi and Australian postgraduate students. Theory and Practice in Language Studies, 5 (2), 247-254.

Bamberg, M. (2011). Who am I? Narration and its contribution to self and identity. Theory \& Psychology, 21(1), 3-24.

Benwell, B., \& Stokoe, E. (2006). Discourse and identity. Edinburgh, UK: Edinburgh University Press.

Dabrowska, E., \& Street, J. (2006). Individual differences in language attainment: Comprehension of passive sentences by native and non-native English speakers. Language Sciences, 28(6), 604- 615.

Edwards, D. (2006). Facts, norms and dispositions: practical uses of the modal verb would in police interrogations. Discourse Studies, 8(4), 475-501. doi:?/ Retrieved from http://www.

Edwards, D., \& Potter, J. (2005). Discursive psychology, mental states and descriptions. In H. Te Molder, \& J. Potter (Eds.), Conversation and cognition (pp.241-259). Cambridge: Cambridge University Press.

Eggins, S. (2004). An Introduction to systemic functional linguistics $\left(2^{\text {nd }} \mathrm{ed}\right.$. London: Continuum.

Firth, J. R. (1957). Modes of meaning. In J. R. Firth (Ed.), Papers in linguistics, 1934-1951 (pp. 190-215). London: Oxford University Press.

Halliday, M. A. K, \& Matthiessen, C. M. I. M. (2004). An introduction to functional grammar (3 ${ }^{\text {rd }}$ ed.). London: Arnold.

Halliday, M. A. K. (1990). New ways of meaning: The challenge to applied linguistics. Journal of Applied Linguistics, 6, Ninth World Congress of Applied Linguistics Special Issue. The Greek Applied Linguistics Association (GALA) (Thessaloniki), 7-36.

Halliday, M. A. K. (1994). An introduction to functional grammar. London: Edward Arnold.

Halliday, M. A. K. (2004). The spoken language corpus: A foundation for grammatical theory. Language and Computers, 49, 11-38.

Halliday, M. A. K. (1970). Functional diversity in language, as seen from a consideration of modality and mood in English. Foundations of Language 6 (3), 322-361.

Hasan, R. (2009). Wanted: A theory for integrated sociolinguistics. London: Equinox.

Hawes, T. (2010). Thematic progression and rhetoric in Sun and Times editorials: 1991-2008. Rice Working Papers in Linguistics. Spring, 2, 39-51.

Hoey, M. (2004). The textual priming of lexis. In G. Aston, S. Bernardini, \& D. Stewart (Eds.), Corpora and Language Learners (pp. 21-41). Philadelphia: John Benjamins.

Hyland, K. (2001). Bringing in the reader: Addressee features in academic articles. Written Communication, 18(4), 549-574.

Lu, A. (2013). A Functional Grammar Approach to Analysing Asian Students' Writing. American Journal of Educational Research, 1(2), 49-57

Padmaja, S., Fatima, S.S., \& Bandu, S. (2014). Evaluating sentiment analysis methods and identifying scope of negation in Newspaper articles. International Journal of Advanced Research in Artificial Intelligence, 3(11), 1-6.

Rashid, R.A, Rahman, M. F. A., \& Rahman, S. B. A. (2016). Teachers'engagement in social support process on a networking site. Journal of Nusantara Studies, 1(1), 34-45.

Rashid, R.A, Wahab, Z., Yunus, K., Ismail, N. S., Yusof, N., Omar, S. S., \& Azmi, M. N. L. (2016). English language teachers as a dissenter on a social networking site. International Journal of Applied Linguistics and English Literature, 5(4), 72-78.

Rashid, R.A. (2016). Topic continuation strategies employed by teachers in managing supportive conversations on Facebook Timeline. Discourse Studies, 18(2), 188-203.

RM2.37bil spent on NS. (2008, May 16). The Star. Retrieved from http://www.malaysia-today.net/rm237bilspent-on-ns-programme/

Sinclair, J. M. H. (1991). Corpus, concordance, collocation. Oxford: Oxford University Press.

Sinclair, J. M. H. (1998). The lexical item. In E. Weigand (Eds.), Contrastive lexical semantics (pp. 1-24). Amsterdam: John Benjamins.

Swales, J. M. (1990). Genre analysis. Cambridge: Cambridge University Press.

Thompson, G. (2004). Introducing functional grammar ( $2^{\text {nd }}$ ed.). London: Hodder Education.

Trenkic, D., Mirkovic, J., \& Altmann, G. T. M. (2014). Real-time grammar processing by native and non-native speakers: Constructions unique to the second language. Bilingualism: Language and Cognition, 17(02), 237-257.

Witte, A. D., Hollevoet, J., Dobruszkes, F., Hubert, M., \& Macharis, C. (2013). Linking modal choice to motility: A comprehensive review. Transportation Research Part A: Policy and Practice, 49, 329-341. 